\author{
Piotr J. Fereński \\ ORCID: 0000-0001-5314-4356 \\ Uniwersytet Wrocławski
}

\title{
Krytyka kapitalizmu jako krytyka kultury
}

Abstrakt: Artykuł jest poświęcony publikacjom naukowym i publicystycznym Marka „k-punka” Fishera. Autor stara się ukazać oryginalność myśli angielskiego teoretyka kultury i jego wkład w krytyczną refleksję nad współczesnymi zjawiskami kulturowymi. Fisher zyskał popularność wydaną w roku 2009 roku książką Capitalist Realism: Is There no Alternative. Publikował w takich pismach, jak: „The Guardian”, „The New Statesman”, „The Wire”. W szczególności zajmowała go kultura popularna. Wyrosły z kontrkultury badacz i wykładowca akademicki często angażował się w obronę interesów klasy robotniczej. Tekst ma za zadanie przybliżyć polskiemu czytelnikowi idee Fishera, co łączy się z koniecznością objaśnienia ich źródeł, między innymi w widmontologii Jacques'a Derridy.

Słowa-klucze: marksizm, widmontologia, nowoczesność, ponowoczesność, kapitalizm, neoliberalizm, realizm, kapitalistyczny, lewica

W wydanej w 2018 roku książce Prognozowanie teraźniejszości pod red. Przemysława Czaplińskiego i Joanny B. Bednarek polski socjolog i kulturoznawca Jan Sowa, pisząc o trwałych skutkach, jakie wywarł na współczesności system kapitalistyczny, zauważał, że neoliberalizm oznacza dziś fazę rozwoju gospodarki wolnorynkowej, w której całkowitej destrukcji ulegają wszelkie zdobycze społeczne, jakie w XX wieku udało się osiągnąć za sprawą dążeń stworzenia „opiekuńczego państwa dobrobytu". Jednocześnie Sowa twierdzi, że kres kapitalistycznej nowoczesności, wyznaczający najbliższą i dalszą przyszłość, daje się opisać w kategoriach zacinania się mechanizmu rozszczepiania czasu i przestrzeni. Odwołując się do wywodów Immanuela Wallersteina i Jasona W. Moore'a (autora głośnej publikacji Capitalism in the Web of Life), argumentuje, że funkcjonowanie kapitalizmu opierało się na łatwej dostępności pracy, żywności, energii i surowców.

Do tego dodać należy możliwość taniego wykonania dwóch procedur rozszczepienia: przestrzennej i czasowej eksternalizacji społecznie negatywnych konsekwencji procesu akumulacji. To wszystko obecnie dobiega końca - surowce się wyczerpują, praca staje się coraz droższa, a koszty środowiskowe związane $\mathrm{z}$ akumulacją okazują się nie tylko coraz wyższe, ale osiągają też postać chaosu klimatycznego [...]. Do tego doszedł nie tylko bunt peryferii — tych zewnętrznych, w postaci np. islamskiego terroryzmu, i tych wewnętrznych, przybierających postać popu-

Prace Kulturoznawcze 23, 2019, nr 1

(C) for this edition by CNS 
lizmu — ale także koniec przyszłości, czyli kryzys wszelkiego rodzaju zadłużenia: hipotecznego, konsumpcyjnego, suwerennego i każdego innego ${ }^{1}$.

Zdaniem Sowy, wykorzystując psychoanalityczne kategorie, sytuację tę można określić mianem traumatycznego powrotu „Realnego”, to jest „tego, co wyparte i zanegowane, a jednocześnie fundamentalne dla działania całego systemu"'2. To interesujące spostrzeżenie przywodzi na myśl idee przedstawione przed kilku laty przez brytyjskiego teoretyka i krytyka kultury Marka „k-punka” Fishera, autora Capitalist Realism: Is There no Alternative, a zarazem publicysty zaangażowanego na rzecz obrony interesów klasy robotniczej. Niniejszy artykuł poświęcony jest dość intrygującym, a jednocześnie stosunkowo mało znanym polskiemu czytelnikowi konceptom Fishera. Ich przypomnienie musi się łączyć z koniecznością ukazania intelektualnych inspiracji „k-punka”, między innymi widmontologii Jacques'a Derridy.

Zanim jednak powiemy więcej o samym Fisherze, należy przedstawić kilka uwag, które nawiązują do prac przywoływanego Sowy i innych badaczy należących do młodszego pokolenia polskich kulturoznawców. Uwagi te związane są z przemianami systemowymi, jakie dokonały się w Polsce przed trzema dekadami. Otóż można zaryzykować stwierdzenie, że po roku 1989 w krajach byłego bloku wschodniego w nauce odcięto się od marksizmu. Popularne stały się różne inne nurty myślowe, niekiedy nieco złośliwie określane mianem „modnych bzdur”. Polską humanistyką najpierw władały podmuchy postmodernizmu, potem mieliśmy do czynienia $\mathrm{z}$ wirem najróżniejszych -izmów, których obecnie niemal nikt nie jest już w stanie wymienić. Nie sposób doliczyć się zwrotów, jakie wykonaliśmy na oceanie idei, obejmujących badania nad kulturą. Nie znaczy to oczywiście, że w tym czasie o autorze Kapitału nigdzie nie było można usłyszeć ${ }^{3}$, niemniej

${ }^{1}$ J. Sowa, Kres kapitalistycznej nowoczesności, [w:] Prognozowanie teraźniejszości, red. P. Czapliński, J.B. Bednarek, Gdańsk 2018, s. 28.

2 Ibidem, s. 29.

3 Przykładem może być wydana w roku 2010 książka Aktualność Marksa, efekt dwuletniego seminarium naukowego, które zainicjował swym wykładem Marks dla naszych czasów filozof kultury i polityki Leszek Koczanowicz. Redaktorzy tomu we wstępie pisali: „Marks niepokoi. Ponownie. Dociekliwością i dogmatyzmem, przenikliwością, zaangażowaniem, natarczywością, profetyzmem, adaptacjami... Podskórnie, namacalnie, nieświadomie, krytycznie czy ślepo i namiętnie, z rozmysłem, demonicznie lub jako farsa dociera wraz z kolejnym echem naszych czasów, przenika życie codzienne i zmienne obszary rodzimych kultur, dalece poza nie wykracza, opalizuje znaczeniami, wpisuje się i wymyka zamieszkując niejedno imię, rzuca długi bolesny cień, dla innych rozjaśnia mroki nowoczesności, dominacji i wyzysku. [...] odsłania swą niewygasłą moc kulturotwórczą, która prowokuje pokolenia badaczy, entuzjastów i krytyków do podjęcia kwestii aktualności jego dorobku, jak również licznych wpływowych tradycji, jakie wliczają go w poczet swoich prekursorów". W Aktualności Marksa, oprócz tekstów rodzimych badaczy, zamieszczono także thumaczenia fragmentów prac takich autorów, jak Cornelius Castoriadis, Jon Elster czy Jacques Derrida. Zawierały one oceny dotyczące tego, co z Marksowskiej spuścizny wydaje się dziś anachroniczne, a co „pozostaje w mocy”. Castoriadis wskazuje na antonimiczność myśli Marksa,

Prace Kulturoznawcze 23, 2019, nr 1

(C) for this edition by CNS 
jeszcze do niedawna na dźwięk jego nazwiska na twarzach większości rodzimych uczonych pojawiała się wiele mówiąca kontorsja. Dziś nazwisko to przywołujemy coraz częściej, wymawiamy coraz wyraźniej, z coraz większą odwagą. Nie tylko robimy przypisy do spuścizny Marksa i jego kontynuatorów, lecz także rozmawiamy o niej podczas zajęć ze studentami, na seminariach, konferencjach, a także podczas publicznych dyskusji i spotkań. Odnosimy ją do zjawisk rzeczywistości nas otaczającej, do problemów, z jakimi musimy się współcześnie mierzyć, między innymi tych opisywanych przez Sowę. Nieco tak, jak gdybyśmy brali sobie do serca słowa Derridy wypowiedziane wiosną 1993 roku w trakcie wykładów na Uniwersytecie Kalifornijskim w Riverside (w ramach sesji „,Whither Marxism?”), opublikowane potem w tomie o intrygującym tytule Widma Marksa:

unikanie lektury i reinterpretacji Marksa, unikanie dyskusji o Marksie — poza akademicką , ,lekturą" i „dyskusją” — zawsze będzie błędem. Dotyczy to także kilku innych myślicieli. Będzie to błąd coraz poważniejszy, wskazujący na brak odpowiedzialności teoretycznej, filozoficznej i politycznej. Odkąd maszyna dogmatyczna i „marksistowskie” aparaty ideologiczne (państwa, partie, komórki, związki zawodowe i inne miejsca produkcji doktrynalnej) są w zaniku, nie ma już żadnego usprawiedliwienia, które pozwalałoby nam odrzucić tę odpowiedzialność — pozostają jedynie wymówki. Bez lektury Marksa nie będzie żadnej przyszłości. Nie bez Marksa nie będzie żadnej przyszłości bez Marksa, bez pamięci o Marksie, bez jego dziedzictwa: w każdym razie, bez rozumianego w określony sposób Marksa, bez jego geniuszu i jego ducha [...], dziedzictwo Marksa było - i wciąż pozostaje, i pozostawać będzie — absolutnie i na wskroś decydujące. Nie trzeba być marksistą lub komunistą by zaakceptować ten oczywisty fakt ${ }^{4}$.

Derrida dopowiada, że żyjemy w „świecie” czy też — jak wolą niektórzy — w „,kulturze”, noszącej w swej głębi znamię owego wielkiego dziedzictwa ${ }^{5}$. Uznawany za postmodernistę francuski filozof deklaruje, że największą pokusą, jakiej musi się oprzeć, jest opowieść o tym, czym dla doświadczenia jego pokolenia był marksizm i quasi-ojcowska figura samego Marksa. Następnie przechodzi do interesującej krytyki idei końca historii. Bardziej istotna z punktu widzenia niniejszego artykułu jest jednak uwaga poczyniona przez niego nieco wcześniej i dotycząca nieodzowności oraz pilności lektury Manifestu komunistycznego. Otóż Derrida zwraca uwagę na doniosłość słów Fryderyka Engelsa z Przedmowy do wydania angielskiego z roku 1888, odnoszących się do historyczności oraz kontekstowości każdego dzieła — również Manifestu komunistycznego — i związanej z tym

z jednej strony podkreślającego znaczenie wolności jednostki i emancypacji, z drugiej wagę deterministyczne ujętych praw historii, w których istnienie raczej mało kto dzisiaj wierzy. Z kolei dla Elstera do przestarzałych elementów koncepcji trewirczyka należy nie tylko teleologia, lecz także materializm dialektyczny, socjalizm naukowy i teoria ekonomiczna. Ważne pozostają natomiast: teoria ideologii (choć z pewnymi zastrzeżeniami), teoria wyzysku, teoria konfliktów klasowych, teoria wyobcowania (alienacji), metoda dialektyczna, idea dobrego życia człowieka, a także teoria zmiany technicznej (M. Pancewicz-Puchalska, R. Włodarczyk, Wstęp, [w:] Aktualność Marksa, red. M. Pancewicz-Puchalska, R. Włodarczyk, Wrocław 2010, s. 6).

${ }^{4}$ J. Derrida, Widma Marksa, przeł. T. Załuski, Warszawa 2016, s. 35-36.

5 Ibidem.

Prace Kulturoznawcze 23, 2019, nr 1

(C) for this edition by CNS 
konieczności transformacji zawartych w nim idei. Łączy się ona z pełną świadomością nieprzewidywalności rozwoju wiedzy i technologii, a także uwarunkowań (bądź też „danych”) politycznych. „Żaden inny tekst nie wydaje się również przenikliwy, jeśli chodzi o dokonujące się uświatowienie [mondialisation] polityczności, a także nieredukowalną rolę techniczności i medialności w ruchu najbardziej myślącej myśli [...]"6.

W innym miejscu Widm słowom o pilności (w podwójnym znaczeniu) lektury Manifestu komunistycznego towarzyszą określenia „nakaz” i „wezwanie”. Derrida przestrzega przy tym przed intelektualnym „rozgrywaniem” Marksa przeciw marksizmowi, co łączy się z osłabianiem imperatywu politycznego poprzez akcentowanie filozoficznego znaczenia prac niemieckiego badacza. To swoista moda kulturowa zdaniem Francuza dominowała w szczególności w świecie uniwersyteckim. Taka depolityzacja thumi rewolucyjną siłę dzieła Marksa (i Engelsa), oddala bunt, zryw, unicestwia otwartość na to, co ma nadejść. Innymi słowy, Marks może wrócić, choć nie w postaci wezwania do rewolucji. Transformacja w tym kontekście ograniczona zostaje do (akademickiej) interpretacji. Wywody autora Kapitału nie są już traktowane jako nawoływanie do przekształcania świata. Zamiast tego wchodzą do kanonu podstawowych tekstów filozoficznych. Derrida sprzeciwia się owej „teoretycznej znieczulicy”, choć dostrzega jednocześnie istotną rolę opisywanego podejścia filozoficzno-filologicznego. Swoje wystąpienie określa przy tym jako gest polityczny. Podkreśla, że dostrzegana przez wielu badaczy heterogeniczność Marksowskiego dyskursu (nieprzekładalność wymiarów - politycznego i naukowego) nie jest jego słabością, lecz czymś, co umożliwia otwarcie na to, co nadchodzi - hamletowskie to be, or not to be. Nie chodzi bowiem Derridzie o „obecność” tytułowego widma (bądź widm), ale o samą jego „możliwość” - możliwość bycia — o coś, co przychodzi do nas za sprawą Marksa. Wobec orzekania o „końcu” marksizmu, historii itp., to jest myślenia o charakterze finalistycznym, przeciwstawione zostają słowa, jakie niemiecki filozof miał skierować pod koniec swojego życia do przyjaciela, Engelsa: „Pewne jest tylko jedno: że nie jestem marksistą"8.

Czemu służy owa „dekonstrukcja Marksa”? Otóż te wątki Derridiańskiej refleksji nad spuścizną jednego z twórców Manifestu komunistycznego, w szczególności kwestie pokoleniowego doświadczenia/obciążenia, konieczności i pilności lektury, uniwersyteckiej depolityzacji jego prac czy „,kultury teoretycznego znieczulenia" oddalającej to, co może nadejść, a zatem wszystko, co wiąże się $\mathrm{z}$ transformacją i działaniem rozumianym jako przeciwieństwo filologicznej interpretacji, należy widzieć jako najistotniejsze elementy dzisiejszych dyskusji nad filozofią Marksa (zwłaszcza w Polsce czy szerzej dawnym bloku wschodnim).

${ }^{6}$ Ibidem, s. 35.

7 Ibidem, s. 62.

${ }^{8}$ K. Marks, F. Engels, Listy wybrane, Warszawa 1951, s. 545, cyt. za: J. Derrida, Widma ..., s. 67. 
Poza warunkami, na jakich „Marks może wrócić”, w kontekście transformacji idei warto rozważyć również wspomniany problem historyczności i otwartości „dzieła”, co łączy się między innymi ze wzmiankowaną już kwestią nieprzewidywalności rozwoju wiedzy i technologii oraz nowych danych/zmiennych politycznych. Nurtuje także to, czy wysławiane przez Derridę wnikliwe diagnozy zawarte w Manifeście komunistycznym da się w jakiś sposób „przełożyć” na analizy współczesnego stadium, w którym to znajduje się globalizacja polityczności, a także ściśle związana z nim (nieredukowalna) rola techniki i mediów w czymś, co można nazwać „ruchem myśli”.

Zanim jednak, odwołując się do twórczości Marka „k-punka” Fishera, podejmiemy próbę odpowiedzi na pytanie o to, co dziś przychodzi do nas za sprawą geniuszu i ducha Marksa, w ślad za autorem Pisma i różnicy musimy podkreślić jeszcze jedną rzecz, istotną nie tylko z punktu widzenia przemian pokoleniowych i odmienności doświadczeń. W pochodzącym z lat sześćdziesiątych poprzedniego stulecia Stowniku języka polskiego pod redakcją Witolda Doroszewskiego jako „marksista” zdefiniowany jest „człowiek o przekonaniach marksistowskich; zwolennik, znawca marksizmu". Za przykładowe podano tam następujące zastosowania owego wyrażenia: „nie potrafił być konsekwentnym marksistą, chociaż zapoznał się z dziełem Marksa”, „dla marksisty problemy walki klasowej obejmują całokształt życia społecznego, znajdując odbicie w każdej z dziedzin działalności i w każdej sferze uczuć ludzkich” oraz „mimo młodego wieku jest wyrobionym marksistą" Język tych przykładów w ciągu ostatnich dekad nabrał anachroniczności. Był kojarzony niemal wyłącznie z demagogicznym dyskursem publicznym cechującym karykaturalny system polityczno-ekonomiczny epoki PRL. Obecnie wyrażenie ,walka klas" dla większości osób - szczególnie tych, które żyły w realiach socjalizmu — wciąż wydaje się brzmieć „,archaicznie” i „kuriozalnie”, niemniej dla znacznej części przedstawicieli młodszego pokolenia badaczy (zob. J. Sowa), a także dla aktywistów czy działaczy społecznych, samo pojęcie „klasy”, „klasowości” i „konfliktu klasowego" nie jest już pustym (niejako pozbawionym odniesień) sloganem, pozbywa się też swego negatywnego aksjotycznego obciążenia. Nie oznacza to jednak powrotu takich autoidentyfikacyjnych określeń jak „marksista”, o „komuniście" nawet nie wspominając. Nie trzeba być marksistą, by zgadzać się w wielu kwestiach z Marksem; nie trzeba podzielać przekonań marksistowskich, by mówić o sprawiedliwości, to jest myśleć w kategoriach „nakazu” i „,wezwania”"10; nie

\footnotetext{
9 Stownik języka polskiego, red. W. Doroszewski, Warszawa 1996.

${ }^{10}$ Nie chodzi o sprawiedliwość w ugruntowanym na wendecie czy rewanżyzmie rozumieniu jurydycznym ani też o znaczenie etyczne. Derrida, odwołując się do Martina Heideggera, pisze o sprawiedliwości w kategoriach samego nadchodzącego zdarzenia. Ontologicznie idzie przy tym o coś więcej niż o dialektykę negatywną. Otóż „konieczne rozspojenie, uniemożliwiający totalizację warunek sprawiedliwości, jest również rozspojeniem tego, co obecne — a w konsekwencji jest samym warunkiem tego, co obecne, i obecności tego, co obecne. W tym właśnie rozspojeniu będzie się zawsze zapowiadać i zaczynać dekonstrukcja jako myśl daru i niedającej się zdekonstruować spra-
}

Prace Kulturoznawcze 23, 2019, nr 1

(C) for this edition by CNS 
trzeba być zwolennikiem marksizmu, by oczekiwać nadejścia „nowego”; czy też w końcu być wyjątkowym znawcą marksizmu, by dostrzegać niezwykłą przenikliwość części wpisujących się w ten nurtu analiz. Dowodzą tego prace przynajmniej kilku współczesnych intelektualistów, w tym właśnie „k-punk”.

Próbując odpowiedzieć na pytania o dzisiejsze znaczenie „zawołania” zawartego w Manifescie komunistycznym, przypomnijmy zatem koncepcje tragicznie zmarłego przed dwoma laty brytyjskiego kulturoznawcy. Jeden z poświęconych mu w piśmie „The Nation” artykułów nosił znamienny tytuł The Marxist Pop-Culture Theorist Who Influenced a Generation. Otóż można tu zaryzykować stwierdzenie, że jeśli $\mathrm{w}$ gronie najważniejszych dwudziestowiecznych marksistów i postmarksistów wymieniać Theodora W. Adorna, Louisa Althussera, Waltera Benjamina, Johna Bergera, Mieczysława Bermana, Pierre'a Bourdieu, Frantza Fanona, Antonia Gramsciego, Stuarta Halla, Maxa Horkheimera, Fredrica Jamesona, Györgya Lukácsa, Herberta Marcusego i Jacques'a Rancière'a, to w XXI wieku do tej listy należałoby dopisać nie tylko Slavoja Žižka (sytuującego się raczej na pograniczu stuleci) czy francuskiego ekonomistę Thomasa Piketty'ego z jego Kapitatem XXI wieku, lecz także właśnie „k-punka”. Zresztą inspirował się on dziełami wielu spośród wymienionych autorów. Dla stworzonego i spopularyzowanego przez niego pojęcia capitalist realism istotna była koncepcja ideologii Althussera, a także prace Jamesona i Žižka. Z kolei dla teorii ,hauntology”, czyli widmontologii lub duchologii $^{11}$, kluczowe były oczywiście wspomniane Widma Marksa. Fisher w interesujący sposób wykorzystał wywody Derridy, by opisać, jak współczesna kultura nawiedzana jest przez ,utraconą przyszłość” nowoczesności, czyli przez to, co „,nie nadeszło" (jeszcze?). Odpowiedzialnością za owo nienadejście czy też przerwanie procesu modernizacji obarczył ponowoczesność i neoliberalizm. Tę pierwszą obwinił za depolityzację kultury i pozbawienie jej ducha progresywności (,rozpuszczenie” idei postępu i awangardowości w nostalgii, ironii, pastiszu itp.), tego drugiego zaś za pozbawienie sztuki mocy oddziaływania. Zadanie widmontologii widział w dogłębnym rozpoznaniu impasów nowoczesności. Badanie widm miało być swoistą formą oporu wobec rezygnacji z pragnienia przyszłości (zob. przypis 6) ${ }^{12}$.

wiedliwości. Niewątpliwie sprawiedliwość stanowi niedekonstruowalny warunek dekonstrukcji, ale jest to warunek, który sam znajduje się w procesie dekonstrukcji i pozostaje — musi pozostawać gdyż właśnie na tym polega tu nakaz” (J. Derrida, Widma..., s. 57). Bez tego nakazu nie może być mowy o przyszłości, wezwaniu, obietnicy czy pragnieniu (określanym przez niego jako ,pustynny mesjanizm"). Samego Marksa oczywiście interesowała przede wszystkim sprawiedliwość dystrybucyjna - przeciwieństwo wyzysku.

${ }^{11} \mathrm{Na}$ temat ,hauntology” czy „duchologii” Derridy w Polsce pisał między innymi Andrzej Marzec, Widmontologia. Teoria filozoficzna i praktyka artystyczna ponowoczesności, Warszawa 2015.

${ }^{12}$ Fascynacje Fishera „widmami modernizmu” mają odzwierciedlenie już w samym tytule jego popularnej książki Ghosts of My Life: Writings on Depression, Hauntology and Lost Futures, Winchester 2014.

Prace Kulturoznawcze 23, 2019, nr 1

(C) for this edition by CNS 
Twórczość „k-punka” wydaje się zatem szczególnie istotna dla krytycznej refleksji nad współczesnymi zjawiskami kulturowymi. Mark Fisher, autor wspomnianej już książki Capitalist Realism: Ist There No Alternative (2009), był krytykiem oraz teoretykiem kultury, który publikował w takich pismach, jak „The Guardian”, „The New Statesman”, „The Wire”. W szczególności zajmowała go muzyka popularna, ale w swych analizach bynajmniej nie ograniczał się do niej, a na jego zaangażowanie społeczne zwracałem już uwagę. W swym bodaj najsłynniejszym, pochodzącym z 2013 roku, eseju Wyjście z Zamku Wampirów starał się zidentyfikować przyczyny, które doprowadziły do sytuacji, w jakiej zagadnienie klasy (czy walki klas) zniknęło w Zjednoczonym Królestwie z lewicowego dyskursu. Zastąpił je wszechpanoszący się moralizm. Miejsce solidarności zajęły wina i strach. Doszło do tego jednak nie pod wpływem prawicowej retoryki („terroru”), ale mieszczańskiego subiektywizmu. Fisher wskazywał na dwie podstawowe libidalno-dyskursywne konfiguracje odpowiedzialne za infekcję ruchu lewicowego. Pierwsza z nich to właśnie tytułowy Zamek Wampirów. Ma on specjalizować się głównie

w krzewieniu poczucia winy. Jego siłą napędową są księżowskie pragnienia ekskomunikowania i potępiania, akademicko-pedantyczne pragnienia jak najszybszego wytknięcia błędów oraz hipsterskie żądze znalezienie się w modnej klice ${ }^{13}$.

„K-punk” podkreślał, że atakowanie owej warowni jest dość ryzykowne, łatwo bowiem przy tym ulec poczuciu niweczenia wysiłków na rzecz zwalczania rasizmu, seksizmu, homofobii. Wampiry za każdym razem gotowe są zrobić wszystko, aby możliwie jak najbardziej spotęgować u atakujących takie wrażenie:

Zamek nie ma jednak monopolu na podejmowanie tych wysiłków, wręcz przeciwnie, można go postrzegać jako ich mieszczańsko-liberalne wypaczenie, odbierające im rozpęd. [...] powstał, kiedy próby uniknięcia etykietek rozdzielanych wedle kategorii tożsamościowych przerodziły się w misję uzyskania „tożsamości” uznawanych przez mieszczańskich Innych ${ }^{14}$.

Zdaniem „k-punka” w ramach współczesnego dyskursu publicznego moraliści, akademiccy pedanci i hipsterzy oddzielają kategorię klasy od innych kategorii, to jest płci społeczno-kulturowej czy rasy itp., dezawuując de facto jej znaczenie. Żywiące się energią i niepokojem przedstawicieli młodego pokolenia (w szczególności studentów) wampiry, ustawiają siebie w pozycji marginalizowanej, ale zarazem jedynej stawiającej opór „ofiary”. W rzeczywistości jednak dążą wyłącznie do skupiania władzy i majątku. Ich główną strategią jest przekształcanie cierpienia konkretnych grup w kapitał intelektualny (czy dokładniej ,,akademicki”). Można tu mówić nawet o „nowym rynku” cierpienia czy ucisku ${ }^{15}$. Fisher używa

13 M. Fisher, Wyjście z Zamku Wampirów, przeł. K. Zubala, „Nowy Obywatel” grudzień 2017, https://nowyobywatel.pl/2017/12/19/wyjscie-z-zamku-wampirow/ (dostęp: 23 marca 2019).

${ }^{14}$ Ibidem.

${ }^{15}$ Dwa pośród „głównych przykazań” Zamku obejmują: wywoływanie poczucia winy, kiedy to tylko możliwe — w myśl im więcej winy, tym lepiej („Ludzie muszą źle się poczuć, żeby zrozu-

Prace Kulturoznawcze 23, 2019, nr 1

(C) for this edition by CNS 
metafory Zamku dla charakterystyki zjawisk społeczno-kulturowych obserwowanych w Wielkiej Brytanii, niemniej wydaje się ona mieć zastosowanie również wobec sytuacji panującej w innych krajach, w tym w Polsce.

Nieco inaczej jest w przypadku drugiej libidalnej formacji, czyli „neoanarchizmu", którego reprezentanci nazywają siebie anarchistami, przy czym ich ideologiczne zaangażowanie w zasadzie nie wykracza poza komentarze w mediach społecznościowych i sporadyczne protesty (głównie studenckie). Tym, co w głównej mierze wyznacza, a w zasadzie ogranicza, ich perspektywę polityczną oraz ekonomiczną — podobnie zresztą jak mieszkańców Zamku — jest nieumiejętność poznawczego przekroczenia własnego doświadczenia historycznego, niemoc odejścia od tego, co zastane, nieoczekiwanie pojawienia się „nowego”.

W ślad za amerykańską teoretyczką polityki Jodi Dean „k-punk” puentuje, że opisywane przez niego fenomeny nie byłyby możliwe bez rozwoju cyberprzestrzeni. Podstawą pozostają tu mechanizmy czegoś, co można określić mianem kapitalizmu komunikatywnego czy komunikacyjnego (communicative capitalism) ${ }^{16}$. To one odpowiadają za skuteczność działań Zamku i popularność postawy neoanarchistycznej. Fisher, próbując wskazać rozwiązania dla tej sytuacji, postuluje przede wszystkim odrzucenie polityki tożsamościowej i przyjęcie do wiadomości faktu,

\footnotetext{
że nie istnieją tożsamości, a tylko pragnienia i kategorie identyfikacji. Jednym z powodów, dla którego brytyjskie nauki kulturowe są tak ważne - co ujawnił w mocny i poruszający sposób John Akomfrah w swojej instalacji „The Unfinished Conversation” („Niezakończona rozmowa”) [...] jest to, że pomogły nam one odrzucić tożsamościowy esencjalizm. Zamiast unieruchamiać ludzi w łańcuchach istniejących już równań, można traktować każdą artykulację jako prowizoryczną i sztuczną. Nowe artykulacje można zawsze stworzyć. Nikt nie jest w istocie czymkolwiek. Niestety, prawica wykorzystuje ten fakt lepiej niż lewica ${ }^{17}$.
}

mieć powagę sytuacji. Bycie uprzywilejowanym klasowo jest w porządku, jeżeli czujesz się z tego powodu winny i sprawiasz, że ci klasowo niżej od ciebie też czują się winni”) — oraz nieustanne esencjalizowanie („Mimo że płynność tożsamości, różnorodność i mnogość to pojęcia, z którymi mieszkańcy Zamku Wampirów lubią się utożsamiać, częściowo, żeby zamaskować swoje niezmiennie zamożne, uprzywilejowane lub mieszczańskie pochodzenie, zachowanie wroga powinno się zawsze redukować do jednego wzorca. Ponieważ pragnienia napędzające Zamek Wampirów to kapłańskie pragnienia ekskomunikowania i potępiania, trzeba wyraźnie rozróżniać dobro od zła, a to drugie - również redukować", ibidem).

16 J. Dean (Communicative Capitalism: Circulation and the Foreclosure of Politics, „Cultural Politics" 1, 2005, nr 1, s. 51-74) zajmuje się w szczególności wpływem sieciowych technologii komunikacyjnych na transformacje postaw i sposobów zaangażowania politycznego. W jej przekonaniu kapitalizm komunikacyjny jest powodem głębokiej depolityzacji współczesnej kultury, do czego przyczyniać się mają różnego typu „fantazje” (fantasy) pojawiające się w jego obrębie fantazje „obfitości”, „aktywności” (uczestnictwa opartego na fetyszyzacji technologii) czy „całości” (produkcji globalnych wyobrażeń). Zob. ponadto eadem, Publicity's Secret: How Technoculture Capitalizes on Democracy, Cornell 2002; eadem, Reformatting Politics: Information Technology and Global Civil Society, New York 2006.

${ }^{17}$ M. Fisher, Wyjście...

Prace Kulturoznawcze 23, 2019, nr 1

(C) for this edition by CNS 
Jak jednak szybko dodaje „k-punk”, owo odrzucenie „tożsamościowości” możliwe jest jedynie poprzez wzmocnienie pojęcia klasy. Głównym źródłem cierpień człowieka pozostaje bowiem istniejąca struktura klasowa. W słowach przywodzących na myśl przywołane wywody Derridy Fisher zachęca do wychodzenia poza „ramy prefiguracji”, do solidarności, do tworzenia samospełniających się przepowiedni, do walki z mieszczańskim subiektywizmem, którego rozmontowanie pozwoli na pojawienie się nowego uniwersalizmu. Dla Fishera nie znaczy to bynajmniej, że zawsze musimy się z sobą zgadzać:

wręcz przeciwnie: musimy stworzyć warunki, gdzie nieporozumienia mogą zachodzić bez strachu przed wykluczeniem i ekskomuniką. Musimy myśleć strategicznie o tym, jak korzystać z mediów społecznościowych — zawsze pamiętając o tym, że mimo egalitaryzmu, który przypisują im ich twórcy, media te są obecnie terytorium wroga, poświęconym reprodukcji kapitału. Nie oznacza to jednak, że nie możemy wkroczyć na ten teren i zacząć okupować go na potrzeby kształtowania świadomości klasowej ${ }^{18}$.

Wszystko, o czym była mowa, w lapidarnej formie zawiera się w muralu umieszczonym na jednej ze ścian londyńskiego Goldsmiths University:

EMANCIPATORY POLITICS MUST ALWAYS DESTROY
THE APPEARANCE OF A 'NATURAL ORDER', MUST
REVEAL WHAT IS PRESENTED AS NECESSARY AND
INEVITABLE TO BE A MERE CONTINGENCY, JUST
AS IT MUST MAKE WHAT WAS PREVIOUSLY DEEMED
TO BE IMPOSSIBLE SEEM ATTAINABLE

Mark Fisher

$(1968-2017)^{19}$

Kulturoznawczyni, copywriterka i blogerka Agata Tomaszewska w jednym z nielicznych polskojęzycznych tekstów na temat „k-punka” pisała, że centralnym punktem swojej pracy Brytyjczyk uczynił zgubny wpływ panującego systemu ekonomicznego na sferę polityczno-kulturową, a także na zdrowie psychiczne ludzi. Neoliberalizm winił on za „impas” nowoczesności, za jej „utraconą przyszłość”, to jest za to, co „,nie nadeszło”, jednak również za „epidemię chorób psychicznych, takich jak nerwice, depresja i lęki, przy kompletnym braku odpowiedzialności za ich negatywne skutki dla społeczeństw"20. Sam Fisher przez wiele lat cierpiał na depresję. Popełnił samobójstwo 13 stycznia 2017 roku.

18 Ibidem.

19 Jest to wyimek z Capitalist Realism. Nie jest to jednak całość zdania. Przywołane słowa poprzedza fraza: „As any number of radical theorists from Brecht through to Foucault and Badiou have maintained [...]" (M. Fischer, Capitalist Realism: Is There no Alternative?, New Alresford 2009, s. 17).

${ }^{20}$ A. Tomaszewska, Śmierć kogniwojażera, „dwutygodnik.com”, wydanie 228, 01/2018, https:// www.dwutygodnik.com/artykul/7578-smierc-kogniwojazera.html (dostęp: 23 marca 2019).

Prace Kulturoznawcze 23, 2019, nr 1

(C) for this edition by CNS 
Z książek, artykułów i esejów, jakie pozostawił, a także z bloga ${ }^{21}$, który przez lata prowadził, przeziera pesymizm, melancholia i wspomniane już poczucie straty, ale też zarazem wyłania się nowy typ — nieprzejednanej, bezwarunkowej — krytyki kulturowej, obejmującej zależności pomiędzy zjawiskami kultury popularnej, rozprzestrzenianiem się nowych mediów, polityką i gospodarką. Termin „realizm kapitalistyczny” wiązał się nie tylko ze wspomnianą teorią ideologii Althussera czy akceleracjonizmem Nicka Landa ${ }^{22}$, lecz także z obserwacją kryzysu finansowego z 2008 roku. Jedna z podstawowych tez książki Capitalist Realism... głosi, że łatwiej jesteśmy sobie w stanie wyobrazić koniec świata niż koniec kapitalizmu (Sowa widzi kres kapitalistycznej nowoczesności). Daleki od upraszczających rzeczywistość schematów Fisher z dystansem odnosił się do roli mediów społecznościowych, postrzeganych od czasów Arabskiej Wiosny i Occupy Wall Street jako najważniejsze narzędzie oddolnego organizowania się w ramach walki przeciw władzy i systemowi. Przestrzegał przed optymizmem, stale podkreślając, że środki masowego przekazu i komunikacji podporządkowane są reprodukcji kapitału' ${ }^{23}$.

Nieco paradoksalnie po swej śmierci pozostał beneficjentem nowotechnologicznego boomu. W styczniu 2017 roku pojawiła się ogromna liczba nekrologów, hołdów i wpisów na jego cześć. Jak wskazała Tomaszewska, był on

\begin{abstract}
jednym z najważniejszych teoretyków kultury doby internetu. Odgrywał rolę drogowskazu wyznaczał nowe kierunki myślenia i inspirował młode pokolenia badaczy i fascynatów kultury urodzonych w czasach internetu. Dla nich, tak jak dla niego, żywa myśl naukowa nie była zamknięta za murami uniwersytetu, tylko kwitła i buzowała w dyskusjach na forach i blogach, a idee rozprzestrzeniały się za pomocą Twittera i wydawnictw ${ }^{24}$.
\end{abstract}

W optyce „k-punka” kapitalizm był przeciwieństwem tego, co Marks nazywał dobrym życiem. Otóż nie powstał on po to, by człowiek mógł urzeczywistniać swoje twórcze możliwości, lecz po to, by akumulowany był kapitał. Dążenie do samospełnienia zastąpiła czysta konsumpcja. Ludzie są potrzebni systemowi kapitalistycznemu, by zyski mogły być stale pomnażane. Kapitalizm służy jedynie samemu sobie, dewastując przy tym wszelkie relacje czy sprzężenia międzyludzkie, w szczególności te które mają potencjał twórczy i emancypacyjny. Zainicjowana w latach dwudziestych poprzedniego stulecia ekonomizacja nieurynkowionych dotychczas dziedzin życia zaczęła stopniowo unicestwiać kulturowego ducha nowoczesności. Dziś mogą już tylko nawiedzać nas widma - twierdził „k-punk”. Niemożliwe stało się tworzenie czegoś nowego, tak samo jak niemożliwy stał się bunt. Od cierpienia w warunkach tyranii kapitału może nas uwolnić

${ }^{21}$ k-punk.org.

22 Zob. N. Land, Teleoplexy: Notes on Acceleration, [w:] \#ACCELERATE: The Accelerationist Reader, red. R. Mackay, A. Avenessian, Falmouth 2014.

$23 \mathrm{https}$ //www.thenation.com/article/marxist-pop-culture-mark-fisher-kpunk-blog-review/ (dostęp: 23 marca 2019).

${ }^{24}$ A. Tomaszewska, Śmierć...

Prace Kulturoznawcze 23, 2019, nr 1

(C) for this edition by CNS 
jedynie najbardziej radykalny gest, ostateczny akt protestu, odmowa poddania się utowarowieniu, którą — nieco jak w Koali Lukasa Bärfussa ${ }^{25}$ — jest samobójstwo. „Ucieleśnienie” tego wszystkiego widział Fisher w postaci amerykańskiego wokalisty i gitarzysty Kurta Cobaina. Lider zespołu Nirvana zastrzelił się w swoim domu w (najzamożniejszej części) Seattle w 1994 roku. Autor Come as You Are rozumiał impas nowoczesności. Wiedział, że w zasadzie nie da się już ustanawiać „alternatywnych” czy „niezależnych” przestrzeni kultury. Można powtarzać gesty buntu i kontestacji, ale główny nurt i tak będzie w stanie wchłonąć wszystko ${ }^{26}$. Wkrótce po śmierci Cobaina miejsce rozpropagowanego przez niego grunge'u - stylu muzycznego wywodzącego się z robotniczych dzielnic i stanowiącego rekombinację różnych elementów dwudziestowiecznej „kontrkultury” — zajął napędzany przez ogromną machinę show-biznesu hip-hop. To on właśnie stał się paradygmatyczny dla przemysłu rozrywkowego XXI wieku. Można jednak zaryzykować stwierdzenie, że „głośny” tytuł debiutanckiego albumu rapera 50-Centa Get richordietryin przyświeca również tym hipsterom, wampirom, neoanarchistom i akademikom, którzy odżegnują się od popkultury.

Jest jednak pewna nadzieja. „K-punk” idzie tu śladem wspomnianego już Nicka Landa, angielskiego filozofa uznawanego za jednego z twórców teorii społeczno-politycznej określanej jako akceleracjonizm (accelerationism). Jej zasadnicza idea zakłada, że przyspieszenie procesów związanych z rozwojem kapitalizmu i wzmocnienie zawartych w nim tendencji autodestrukcyjnych doprowadzi do jego szybkiego wyczerpania się i upadku. Jakie to tendencje? Otóż pojęcie realizmu kapitalistycznego z jednej strony jest grą słów z określeniem „realizm socjalistyczny”27, z drugiej zaś nawiązuje do Lacanowskiej kategorii „Realnego” (spopularyzowanej również za sprawą Žižka).

${ }^{25}$ L. Bärfuss, Koala, przeł. A. Żychliński Wrocław 2017.

26 „W swej straszliwej biedzie i niemającej celu wściekłości, Cobain dawał wyraz przygnębieniu pokolenia, które przyszło po końcu historii i którego każdy ruch był przewidywany, śledzony, kupowany i sprzedawany, zanim jeszcze miał miejsce. Cobain wiedział, że jest tylko częścią kolejnego spektaklu, że nic nie działa lepiej na rzecz MTV niż protest przeciwko MTV; wiedział, że wszystko, co robi, jest trywialne, wiedział nawet, że konstatowanie tego faktu jest banałem. Impas, który sparaliżował Cobaina, jest dokładnie tym samym impasem, który opisywał Fredric Jameson: analogicznie jak cała postmodernistyczna kultura, Cobain znalazł się »w świecie, w którym innowacja stylistyczna jest niemożliwa, pozostało jedynie naśladować martwe style, zakładać językowe maski, mówić głosami z muzeum wyobraźni«" (M. Fisher, Capitalist Realism..., s. 9). Cytat z Jamesona pochodzi z tekstu Postmodernism and Consumer Society, przygotowanego pierwotnie jako wykład dla Whitney Museum. Podaję w polskim jego tłumaczeniu - F. Jameson, Postmodernizm i społeczęństwo konsumpcyjne, przeł. P. Czapliński, [w:] Postmodernizm. Antologia przekładów, red. R. Nycz, Kraków 1997, s. 197. Amerykański marksista dopowiadał dalej: „Oznacza to jednak, że współczesna czy też postmodernistycza sztuka będzie mówiła o sztuce samej w jakiś nowy sposób; co więcej, oznacza to, jej podstawowe przesłanie wiązać się będzie z nieunikniona klęską sztuki i estetyki, z klęską »nowego«, z uwięzieniem w przeszłości" (ibidem).

27 Jak przyznaje sam Fisher, stosowany przez niego termin „realizm kapitalistyczny” nie jest jego oryginalnym pomysłem. Określenie to zostało użyte już w latach sześćdziesiątych XX wieku przez grupę niemieckich pop-artystów oraz przez Michaela Schudsona w książce z 1984 roku zaty-

Prace Kulturoznawcze 23, 2019, nr 1

(C) for this edition by CNS 
Dla Lacana Realne jest tym, co każda „rzeczywistość” musi stłumić; w rzeczy samej, rzeczywistość składa się z samych tylko represji. Realne jest niereprezentowalnym X, traumatyczną pustką, którą można dostrzec jedynie w złamaniach i niespójnościach pozornej rzeczywistości. Tak więc jedyną strategią przeciwko realizmowi kapitalistycznemu może być powoływanie się na Realne leżące u podstaw rzeczywistości, którą przedstawia nam kapitalizm ${ }^{28}$.

Fisher dostrzega w systemie kapitalistycznym pęknięcia odsłaniające owo Realne. Chodzi przede wszystkim o katastrofy wydarzające się w środowisku naturalnym ${ }^{29}$, które bezpośrednio związane są z wywołanymi przez człowieka zmianami klimatycznymi (w tym z niekontrolowaną eksploatacją zasobów globu), z epidemiami chorób psychicznych oraz z biurokracją. Wśród stanów psychicznych odzwierciedlających neurotyczną kondycję naszych czasów wymienia „refleksyjną impotencję” i „depresyjną hedonię”. Bolączką współczesności nie jest apatia ani też cynizm, lecz fakt, że mimo świadomości tego, że coś jest złe, nie podejmujemy żadnych działań, by to zmienić. Ten stan rodzi różne formy depresji, w tym hedonistyczną, polegającą na zorientowaniu się wyłącznie na to, co w sposób bezpośredni przynosi przyjemność. Innym zjawiskiem stanowiącym rodzaj pęknięcia, niespójności - a być może nawet „akceleratora” — jest biurokracja. Neoliberalni ideolodzy zwykli oskarżać socjalizm o to, że poprzez stałe rozbudowywanie machiny urzędniczej doprowadził do całkowitej nieefektywności gospodarki. Wraz z triumfem neoliberalizmu biurokracja miała ulec znaczącej redukcji. Tymczasem, jak zauważa „k-punk”, dla wielu osób żyjących w późnym kapitalizmie jest przedmiotem codziennego doświadczenia. Jej istnienie sugeruje nie tyle, że kapitalizm nie działa, ile że realnie funkcjonuje on w zupełnie odmienny sposób, niż przedstawia to neoliberalna narracja. Thatcheryzm zniszczył modernizm, zahamował procesy emancypacyjne. Uprzywilejował kapitał kosztem uczestnictwa niższych klas w realnej kulturowej produkcji i zniósł poczucie solidarności. Czy związane z kapitalistycznym imperatywem edukacji niespójności, takie jak biurokracja czy problemy ze zdrowiem psychicznym, pozwalają na „odkrywanie" tego, co stłumione - niereprezentowalnego X? I czy wobec tego istnieją jakieś alternatywy? Trudno odpowiedzieć na to pytanie, ale depolityzacja kultury i teoretyczne znieczulenie na pewno służą oddalaniu tego, co mogłoby nadejść. Jeśli Marks miałby wrócić, to nie po to, by służyć wnikliwym analizom dotyczącym globalnych procesów politycznych i gospodarczych (w tym kwestii pracy, żywności, energii, surowców, chaosu klimatycznego) czy współczesnej roli techniczności i medialności, ale by wywołać, pobudzić, sprowokować działanie.

tułowanej Advertising. The UneasyPersuasion (New York). W obu przypadkach chodziło o parodystycznie nawiązanie do socjalizmu (M. Fisher, Capitalist..., s. 20).

${ }^{28}$ Ibidem, s. 18.

${ }^{29}$ Swoją drogą należy stale pamiętać, że poza widmami Derridy, inspiracją „k-punka” są też idee francuskiego marksisty Alaina Badiou. Jedną z zaproponowanych przez niego kategorii jest „wydarzenie”. Jest ono czymś spoza ontologii, czymś nierozpoznanym. Zob. A. Badiou, Święty Pawet. Ustanowienie uniwersalizmu, przeł. J. Kutyła, P. Mościcki, Warszawa 2007.

Prace Kulturoznawcze 23, 2019, nr 1

(C) for this edition by CNS 
Być może nauki o kulturze powinny się zaangażować w walkę z głównym źródłem cierpień człowieka, jakim są wzmocnione przez neoliberalizm podziały klasowe czy też po prostu niepohamowany, wszechobecny wyzysk.

\section{Critique of capitalism as a critique of culture}

Abstract

The text is devoted to scientific and journalistic achievements of Marek "k-punk" Fisher. The author tries to show the originality of thought of the English theorist of culture and his contribution to the critical reflection on contemporary cultural phenomena. Fisher gained popularity in 2009 with the book Capitalist Realism: Is There No Alternative. He published in such magazines as The Guardian, The New Statesman, The Wire. In particular, he was interested in popular culture. The researcher and academic lecturer - with counter-cultural background - was often involved in defending the interests of the working class. The idea of the article is to familiarize the Polish reader with the concepts of Fisher, which are especially connected with the thought of Jacques Derrida.

Keywords: Marxism, hauntology, modernity, postmodernity, capitalism, neoliberalism, capitalist realism, left

\section{Bibliografia}

Badiou A., Święty Pawet. Ustanowienie uniwersalizmu, przeł. J. Kutyła, P. Mościcki, Warszawa 2007. Bärfuss L., Koala, przeł. A. Żychliński Wrocław 2017.

Dean J., Communicative Capitalism: Circulation and the Foreclosure of Politics, „Cultural Politics” $1,2005, \mathrm{nr} 1$.

Dean J., Publicity's Secret: How Technoculture Capitalizes on Democracy, Cornell 2002.

Dean J., Reformatting Politics: Information Technology and Global Civil Society, New York 2006.

Derrida J., Widma Marksa, przeł. T. Załuski, Warszawa 2016.

Fischer M., Capitalist Realism: Is There no Alternative?, New Alresford 2009.

Fischer M., Ghosts of My Life: Writings on Depression, Hauntology and Lost Futures, Winchester 2014.

Fischer M., Wyjście z Zamku Wampirów, przeł. K. Zubala, „Nowy Obywatel” grudzień 2017, https:// nowyobywatel.pl/2017/12/19/wyjscie-z-zamku-wampirow/ (dostęp: 23 marca 2019).

Jameson F., Postmodernizm i społeczeństwo konsumpcyjne, przeł. P. Czapliński, [w:] Postmodernizm. Antologia przekładów, red. R. Nycz, Kraków 1997.

Land N., Teleoplexy: Notes on Acceleration, [w:] \#ACCELERATE: The Accelerationist Reader, red. R. Mackay, A. Avanessian, Falmouth 2014.

Marzec A.,Widmontologia. Teoria filozoficzna i praktyka artystyczna ponowoczesności, Warszawa 2015.

Pancewicz-Puchalska M., Włodarczyk R., Wstęp, [w:] Aktualność Marksa, red. M. Pancewicz-Puchalska, R. Włodarczyk, Wrocław 2010.

Stownik języka polskiego, red. W. Doroszewski, Warszawa 1996.

Prace Kulturoznawcze 23, 2019, nr 1

(C) for this edition by CNS 
Sowa J., Kres kapitalistycznej nowoczesności, [w:] Prognozowanie teraźniejszości, red. P. Czapliński, J.B. Bednarek, Gdańsk 2018.

Tomaszewska A., Śmierć kogniwojażera, „dwutygodnik.com”, wydanie 228, 01/2018, https://www. dwutygodnik.com/artykul/7578-smierc-kogniwojazera.html (dostęp: 23 marca 2019).

Prace Kulturoznawcze 23, 2019, nr 1

(C) for this edition by CNS 